This PDF is a selection from an out-of-print volume from the National Bureau of Economic Research

Volume Title: Resource and Output Trends in the United States Since 1870

Volume Author/Editor: Moses Abramovitz

Volume Publisher: NBER

Volume ISBN: 0-87014-366-2

Volume URL: http://www.nber.org/books/abra56-1

Publication Date: 1956

Chapter Title: Resource and Output Trends in the United States Since 1870

Chapter Author: Moses Abramovitz

Chapter URL: http://www.nber.org/chapters/c5650

Chapter pages in book: (p. 1 - 23) 


\title{
Resource and Output Trends in the United States since 1870
}

\author{
MOSES ABRAMOVITZ
}

OCCASIONAL PAPER 52

NATIONAL BUREAU OF ECONOMIC RESEARCH, INC. 1956 
Reprinted from the American Economic Revietv Library of Congress catalog card number: 56-9226.

Price $\$ .50$ 


\title{
NATIONAL BUREAU OF ECONOMIC RESEARCH
}

\author{
1956 \\ OFFTCERS
}

\author{
Harry Scherman, Chairman \\ Gottfried Haberler, President
}

George B. Roberts, Vice-President and Treasurer

W. J. Carson, Executive Director

DIRECTORS AT LARGE

Wallace J. Campbell, Director, Cooperative League of the USA

Solomon Fabricant, New York University

Albert J. Hettinger, Jr., Lazard Frères and Company

Oswald W. Knauth, Beaufort, South Carolina

H. W. Laidler, Executive Director, League for Industrial Democracy

Shepard Morgan, Norfolk, Connecticut

George B. Roberts, Vice-President, The First National City Bank of New York

Beardsley Ruml, New York City

Harry Scherman, Chairman, Book-of-the-Month Club

George Soule, Bennington College

N. I. Stone, Consulting Economist

J. Raymond Walsh, New York City

Joseph H. Willits, Director, The Educational Survey, University of Pennsylvania

Leo Wolman, Columbia University

Donald B. Woodward, Vick Chemical Company

Theodore O. Yntema, Vice-President-Finance, Ford Motor Company

\section{DIRECTORS BY UNIVERSITY APPOINTMENT}

E. Wight Bakke, Yale

Arthur F. Burns, Columbia

Melvin G. de Chazeau, Cornell

G. A. Elliott, Toronto

Frank W. Fetter, Northwestern

H. M. Groves, Wisconsin
Gottfried Haberler, Harvard

Clarence Heer, North Carolina

R. L. Kozelka, Minnesota

C. Arthur Kulp, Pennsylvania

T. W. Schultz, Chicago Jacob Viner, Princeton

DIRECTORS APPOINTED BY OTHER ORGANIZATIONS

Percival F. Brundage, American Institute of Accountants

Harold G. Halcrow, American F arm Economic Association

S. H. Ruttenberg, Congress of Industrial Organizations

Murray Shields, American Management Association

Boris Shishkin, American Federation of Labor

W. Allen Wallis, American Statistical Association

John H. Williams, American Economic Association

Harold F. Williamson, Economic History Association

RESEARCH STAFF

Solomon Fabricant, Director of Research

Geoffrey H. Moore, Associate Director of Research

Moses Abramovitz

Morris A. Copeland

David Durand

Milton Friedman

Raymond W. Goldsmith

Millard Hastay

W. Braddock Hickman

Daniel M. Holland

Thor Hultgren
John W. Kendrick Simon Kuznets

Clarence D. Long

Ruth P. Mack

Ilse Mintz

G. Warren Nutter

Lawrence H. Seltzer

George J. Stigler Leo WoIman

Herbert B. Woolley 


\section{Relation of the Directors}

\section{to the Work and Publications \\ of the National Bureau of Economic Research}

1. The object of the National Bureau of Economic Research is to ascertain and to present to the public important economic facts and their interpretation in a scientific and impartial manner. The Board of Directors is charged with the responsibility of ensuring that the work of the National Bureau is carried on in strict conformity with this object.

2. To this end the Board of Directors shall appoint one or more Directors of Research.

3. The Director or Directors of Research shall submit to the members of the Board, or to its Executive Committee, for their formal adoption, all specific proposals concerning researches to be instituted.

4. No report shall be published until the Director or Directors of Research shall have submitted to the Board a summary drawing attention to the character of the data and their utilization in the report, the nature and treatment of the problems involved, the main conclusions and such other information as in their opinion would serve to determine the suitability of the report for publication in accordance with the principles of the National Bureau.

5. A copy of any manuscript proposed for publication shall also be submitted to each member of the Board. For each manuscript to be so submitted a special committee shall be appointed by the President, or at his designation by the Executive Director, consisting of three Directors selected as nearly as may be one from each general division of the Board. The names of the special manuscript committee shall be stated to each Director when the summary and report described in paragraph (4) are sent to him. It shall be the duty of each member of the committee to read the manuscript. If each member of the special committee signifies his approval within thirty days, the manuscript may be published. If each member of the special committee has not signified his approval within thirty days of the transmittal of the report and manuscript, the Director of Research shall then notify each member of the Board, requesting approval or disapproval of publication, and thirty additional days shall be granted for this purpose. The manuscript shall then not be published unless at least a majority of the entire Board and a two-thirds majority of those members of the Board who shall have voted on the proposal within the time fixed for the receipt of votes on the publication proposed shall have approved.

6. No manuscript may be published, though approved by each member of the special committee, until forty-five days have elapsed from the transmittal of the summary and report. The interval is allowed for the receipt of any memorandum of dissent or reservation, together with a brief statement of his reasons, that any member may wish to express; and such memorandum of dissent or reservation shall be published with the manuscript if he so desires. Publication does not, however, imply that each member of the Board has read the manuscript, or that either members of the Board in general, or of the special committee, have passed upon its validity in every detail.

7. A copy of this resolution shall, unless otherwise determined by the Board, be printed in each copy of every National Bureau book.

(Resolution adopted October 25, 1926 and revised February 6, 1933 and February 24, 1941) 


\title{
RESOURCE AND OUTPUT TRENDS IN THE UNITED STATES SINCE 1870*
}

\author{
By Moses Abramovitz \\ Stanford University
}

\section{Introduction}

This paper is a very brief treatment of three questions relating to the history of our economic growth since the Civil War: (1) How large has been the net increase of aggregate output per capita, and to what extent has this increase been obtained as a result of greater labor or capital input on the one hand and of a rise in productivity on the other? (2) Is there evidence of retardation, or conceivably acceleration, in the growth of per capita output? (3) Have there been fluctuations in the rate of growth of output, apart from the short-term fluctuations of business cycles, and, if so, what is the significance of these swings?

The answers to these three questions, to the extent that they can be given, represent, of course, only a tiny fraction of the historical experience relevant to the problems of growth. Even so, anyone acquainted with their complexity will realize that no one of them, much less all three, can be treated satisfactorily in a short space. I shall have to pronounce upon them somewhat arbitrarily. My ability to deal with them at all is a reflection of one of the more important, though one of the less obvious, of the many aspects of our growing wealth; namely, the accumulation of historical statistics in this country during the last generation.

For the most part, the figures which I present or which underlie my qualitative statements are taken directly from tables of estimates of national product, labor force, productivity, and the like compiled by others. In a few cases I have ventured to compute ratios or extend the tables forward or backward by combining estimates. But no original estimates depending on the compilation or reworking of primary data are included.

\footnotetext{
* I should like to thank Professor Simon Kuznets and Mr. J. W. Kendrick who made available to me certain unpublished estimates of national product, productivity, capital stock, and hours of work. Their contributions are further described in the notes to Table 1. I am grateful to Richard A. Easterlin, Solomon Fabricant, J. W. Kendrick, and G. H. Moore for their critical review of the manuscript and to Mrs. Charlotte Boschan for assisting in its preparation.

This paper has been approved for publication as a report of the National Bureau of Economic Research by the Director of Research and the Board of Directors of the National Bureau, in accordance with the resolution of the Board governing National Bureau reports (see the 35th Annual Report of the National Bureau of Economic Research, May, 1955). It is to be reprinted as No. 52 in the National Bureau's series of "Occasional Papers."
} 
The period since 1870 has an important unifying characteristic in that throughout these eighty years the economy has been growing in response to the complex of cumulative forces which we generally call industrialization. It is quite clear, however, that 1870 was not the beginning of the process of industrialization in this country. The proportion of gainful workers in agriculture fell from 71 per cent in 1820 to 64 per cent in 1850 . It fell another 10 percentage points by 1870 . Steam transport by water and rail was already common when the period begins. The proportion of the gainfully employed engaged in manufacturing and construction rose from 12 to 21 per cent between 1820 and 1870 . Real per capita output rose significantly during the 1850 's. It was set back by the Civil War, but aggregate output wellnigh doubled from 1850 to $1870 .{ }^{1}$ The data before 1870 - and still more before 1850-are highly dubious, but it seems clear that the period since 1870 does not include the entire era of industrialization and rapid income rise in this country. We are, in an important sense, dealing with a period arbitrarily delimited by the availability of fairly reliable comprehensive figures.

It may be of some use if I try to state at the very beginning the three main conclusions of my paper. First, between the decade 1869-78 and the decade 1944-53, net national product per capita in constant prices approximately quadrupled, while population more than tripled. The source of the great increase in net product per head was not mainly an increase in labor input per head, not even an increase in capital per head, as these resource elements are conventionally conceived and measured. Its source must be sought principally in the complex of little understood forces which caused productivity, that is, output per unit of utilized resources, to rise.

Second, it is not clear that there has been any significant trend in the rates of growth of total output and of output per head. It is true that national product estimates, on their face, suggest some decline in the rates of growth-somewhat more clearly for total output; somewhat less clearly for output per capita. It is doubtful, however, whether the data can be accepted with confidence for this purpose and still more doubtful whether the apparent retardation in growth, such as it is, represents the effect of persistent forces. Insofar as one can observe a decline in the rate of growth, its source is not in the productivity of resources, which has continued to grow at a steady, perhaps an accelerat-

\footnotetext{
'These are W. I. King's figures (The Wealth and Income of the People of the United States, Macmillan, 1915, Table XXIII), as deflated by Simon Kuznets ("Long-Term Changes in the National Income of the United States of America since 1870"-hereinafter called "Long-Term Changes"-published in Income and Wealth of the United States, edited by Simon Kuznets, Cambridge, Bowes and Bowes, 1952, p. 240).
} 
ing, pace. Its source has been a decline in the rate of growth of labor input per head and of capital input per head.

Third, the rate of growth of output has not been even. In addition to ordinary business cycles, the rate of growth has risen and fallen since 1870 in long waves of approximately twenty years' duration. Preliminary study suggests that these waves represent, in the main, surges in productivity or resource supply rather than in the proportion of our resources employed. An adequate understanding both of the history of our growth and of our prospects during the next generation depends on our ability to determine whether these surges and relapses are to some significant degree truly recurrent or wholly fortuitous.

\section{The Average Rate of Growth, 1869-1953}

My first problem has to do with the over-all expansion of our economy since 1870 . My principal criterion of growth is net national product per capita in 1929 prices, and since I use Kuznets' data, I follow him in measuring the increase by comparing average product and related data for labor, capital, and so on, for the decade 1869-78 with that for the decade 1944-53.2 Comparisons based on such decade averages eliminate most but, of course, not all the effects of business cycles, which might otherwise serve to distort somewhat our impressions of the long-term rate of growth. They do not protect our measures from the effects of fluctuations longer in duration than business cycles, the so-called "secular swings," which I shall discuss later. It would be better to calculate rates of growth from properly derived trend values. But in measures for a period as long as eighty years, when growth was so rapid, the distortion resulting from secular swings will not prevent us from seeing the broad outlines of the picture, and I judged it unnecessary to calculate statistical trend lines for this purpose.

1. Net national product in the decade 1944-53 stood about thirteen times as high as it had in 1869-78 (Table 1). This increase implies an average rate of growth of 3.5 per cent per annum. Population, however, more than tripled in the same period. Net product per capita, therefore, approximately quadrupled, implying an average rate of growth of 1.9 per cent per annum.

These calculated rates of increase are only rough approximations of the figures we are really after. Long-term estimates of national products are inevitably marred by statistical weaknesses, biases, and uncertainties of conception. (Cf. Kuznets, "Long-Term Changes," pages

\footnotetext{
${ }^{2}$ Professor Kuznets has very kindly permitted me to use his newly revised estimates extended to 1953. These are, as yet, unpublished, but very similar figures are published in "Long-Term Changes." The broad concepts on which the data are based and the methods of estimate are described in that volume, pp. 29-34. The latter have been altered in certain details in ways which Professor Kuznets will describe in a later publication.
} 
33-47.) We must accept the fact that even the most comprehensive and consistent measures of our rate of expansion must be treated with a great deal of reserve.

2. The quadrupling-more or less-of net national product per capita resulted in part from an increase in the input of resources per capita and in part from a rise in the productivity, that is, the output per unit, of representative units of resources. However, the shares of these two elements, insofar as they can be separated, were very different. The input of resources per head of the population appears to have increased relatively little while the productivity of resources increased a great deal. How does this arise?

The input of resources is usually conceived to consist of labor services, including salaried management, and property or capital services, to which is attached the contributions of entrepreneurship made in connection with the investment of capital in industry. If we measure labor services in man-hours, as is usually done, we find that labor in-

TABLE 1

Measures of U.S. Economic Growth, 1869-78 to 1944-53

\begin{tabular}{|c|c|c|}
\hline & & $\begin{array}{c}\text { Relatives for } \\
1944-53 \\
(1869-78=100)\end{array}$ \\
\hline $\begin{array}{l}(1) \\
(2) \\
(3) \\
(4) \\
(5) \\
(6) \\
(7) \\
(8) \\
(9) \\
(10) \\
(11) \\
(12) \\
(13) \\
(14) \\
(15) \\
(16) \\
(17) \\
(18)\end{array}$ & 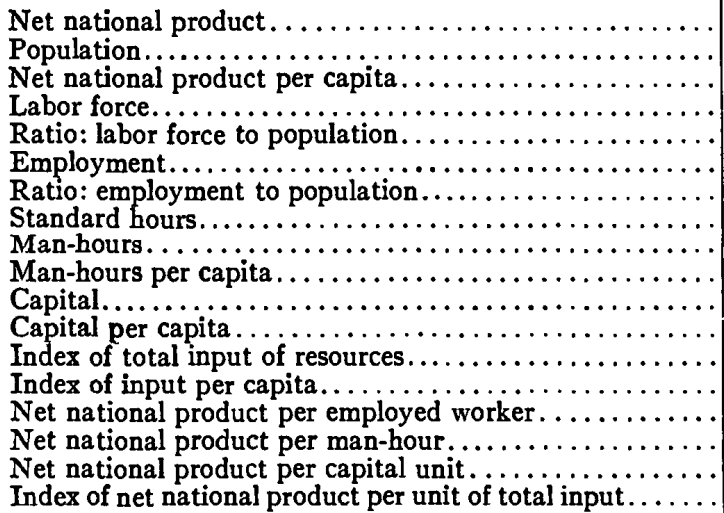 & $\begin{array}{l}1,325 \\
334 \\
397 \\
423(393) \\
127(118) \\
427(396) \\
128(119) \\
73 \\
312(290) \\
94(87) \\
993 \\
297 \\
381(361) \\
114(108) \\
310(334) \\
426(458) \\
134 \\
348(367)\end{array}$ \\
\hline
\end{tabular}

Figures in parentheses exclude armed forces.

All the figures in this table, unless otherwise noted, were drawn from series of averages for overlapping decades running 1869-78, 1874-83, etc.

The units of the data from which the relatives were calculated are shown in the notes to each line.

\section{Line:}

(1) Newly revised estimates by Simon Kuznets (billions of dollars in 1929 prices) to be published and described in the Summary Volume on Capilal Formation and Financing, Part B. 
(2) Ibid., Part E. Decade averages computed from annual data underlying five-year moving averages to be published.

(3) Line (1) $\div$ line (2) (1929 dollars per person).

(4) See line (2).

(5) Line (4) $\div$ line (2) (per cent).

(6) Line (4) less estimated unemployment (millions) as follows: 1869-78 to 1884-93: from J. Schmookler, "The Changing Efficiency of the American Economy, 1869-1938," Review of Economics and Statistics, August, 1952, Table 3, col. (2).

1889-98 to 1939-48: by applying unemployment percentage from Kuznets, "Long-Term Changes," Table 10, col. (1) to his estimates of the civilian labor force and adding armed forces. From 1889-1918, the labor force figures were first divided into agricultural and nonagricultural segments. The unemployment percentages, which for those years represent only nonagricultural unemployment, were applied to the latter only.

1944-53: By applying ratio of civilian employment to civilian labor force as estimated by Census (Survey of Current Business, 1955 Biennial Edition, p. 56) to Kuznets' estimate of civilian labor force and adding armed forces.

(7) Line (6) $\div$ line (2) (per cent).

(8) 1869-78 to 1939-48: from Kuznets, op. cit., Table 7, col. (1). 1944-53: extrapolated on the basis of the movement of estimates kindly supplied to the author by J. W. Ken drick. (Hours per week.)

(9) Line (6) Xline (8) (millions of man-hours per week).

(10) Line (9) $\div$ line (2) (weekly hours per capita).

(11) 1874-83 to 1939-48: Kuznets, op. cit., Table 11, col. (3). Single figures are provided once each decade, 1879 to 1939 , for years running 1879, 1889, etc. In addition there are figures for 1934 and 1944. The given data are assumed to represent averages for decades whose central points they approximate (1879 for 1874-83, etc.). Overlapping decades interpolated where necessary by straight line arithmetic interpolations from both preceding and succeeding observations. The two results were then averaged.

1869-78: Extrapolated from 1874-83 by movement of estimates by Schmookler, op. cit., Table 5, col. (3).

1944-53: Extrapolated from 1939-48 on basis of estimates kindly supplied by J. W. Kendrick (billions of dollars in 1929 prices).

(12) Line (11) $\div$ line (2) (dollars per person).

(13) Weighted index of relatives $(1919-28=100)$, combining man-hours $\times 3$ and capital $\times 1$. Weights represent the relative values of service incomes and property incomes respectively as estimated by J. W. Kendrick for 1929 and supplied to author. Kendrick's relative weights were, more precisely, 72:28.

(14) Weighted index of relatives $(1919-28=100)$, combining man-hours per capita and capital per capita with weights as in line (13).

(15) Line (1) $\div$ line (6) (dollars per employed in 1929 prices).

(16) Line (1) $\div$ line (9) (dollars per man-hour).

(17) Line (1) $\div$ line (11) (cents per dollar of capital).

(18) Index of NNP $\div$ index of total input of resources $(1919-28=100)$.

put per capita declined slightly between the seventies and the present. This resulted from the counteraction of two trends. The labor force ratio, that is, the ratio of labor force to population, grew about 25 per cent as a result of changes in the age composition of the population, because of the shift of people from farms to cities, and because the great increase in the participation of women in work offset the withdrawal of young people to school and of elderly men to earlier retirement. On the other hand, the reduction in working hours more than counterbalanced the increase in the labor force ratio.

- Cf. C. D. Long, The Labor Force under Changing Employment and Income (National Bureau of Economic Research; in press), Chap. XI. While there may have been some difference in the percentage of unemployment between the 1870's and the 1950's, the great decline in working time per member of the labor force was due to a reduction in hours of work. The change in working hours recorded in our table is based on a series appearing in Kuznets' "Long-Term Changes" extended an extra decade on the basis of 
The physical volume of capital, of course, increased much more rapidly than population. An estimate of total capital, which takes account of land, structures, producers' durable equipment, inventories and net foreign claims, increased to nearly ten times its size seventy-five years ago. Capital per head of the population approximately tripled. ${ }^{4}$

What has been the increase in the input of all resources per capita? Suppose we combine our indexes of labor input per capita and of cap-

Kendrick's figures. But other estimates make the long-term decline somewhat less or more. For comparison, the following alternatives are of interest:

$\begin{array}{llcc} & \begin{array}{c}\text { Base } \\ \text { Period }\end{array} & \begin{array}{c}\text { Given } \\ \text { Year or } \\ \text { Period } \\ \text { (1) Kuznets, Standard Hours }\end{array} & \begin{array}{c}\text { Index of } \\ \text { Average Hours } \\ \text { in Given Year } \\ \text { (Base = 100) }\end{array} \\ \text { (2) Dewhurst and Fichlander, } & 1869-78 & 1944-53 & 73 \\ \text { Actual Hours } & 1870-80 & 1950 & 62 \\ \text { (3) Barger, Actual Hours in Commodity } & & & 83 \\ \text { (4) Broduction } & 1869-79 & 1949 & 66 \\ \text { (5) Kurger, Actual Hours in Distribution } & 1869-79 & 1949 & 79 \\ \text { (6) Kendrick, Actual Hours } & 1894-1903 & 1944-53 & 83\end{array}$

Sources:

Line (1)-"Long-Term Changes," Table 7. Figures extended from 1939-48 to 1944-53 on the basis of estimates kindly supplied by J. W. Kendrick.

Line (2)-Dewhurst and Associates, America's Needs and Resources, A New Survey (Twentieth Century Fund, 1955), Appendix 20-4.

Line (3)-Distribution's Place in the American Economy since 1869, Table 5.

Line (4)-Same as line (3).

Line (5)-Same as line (1).

Line (6)-Supplied by J. W. Kendrick.

- Estimates of capital wealth are extremely rough and must be treated with great reserve. While there is no doubt that capital increased much faster than population, we may well doubt whether the relative increase was just that suggested by the figures. Our figures are based on the table presented by Kuznets for the years 1879-1944 "'Long-Term Changes," Table 11). See notes to Table 1. The figures may be compared with $R$. W. Goldsmith's estimates ("Derivation of a Perpetual Inventory of National Wealth since 1896," Studies in Income and Wealth, Vol. 14, National Bureau of Economic Research, p. 18).

\begin{tabular}{lccc} 
& \multicolumn{3}{c}{ Relatives for 1944} \\
\cline { 2 - 3 } & Goldsmith & Kuznets & \\
& $(1900=100)$ & $(1899=100)$ & Ratio \\
& $(1)$ & $(2)$ & $(2) \div(1)$ \\
Land & 133 & 208 & 1.56 \\
Reproducible wealth* & 271 & 344 & 1.27 \\
Total & 216 & 284 & 1.31
\end{tabular}

* Structures, producers' durable equipment, inventories and net foreign claims.

Neither Goldsmith's figures nor Kuznets' are free of serious difficulties due to weaknesses in the statistical sources of capital data and to problems of valuation and defiation. (See Kuznets, op. cit., pp. 79-80, and Goldsmith, op. cit., passim, and following comments by Kuznets.) It is possible that the true increase of capital lies outside the range suggested by both sets of figures. Our figures make no allowance for changes in the service hours of capital comparable with that for labor. There is no statistical basis for such an adjustment. The decline in labor hours is not a reliable indication since capital is often operated on multiple shifts or even continuously. It is not clear whether such practices have grown or declined. 
ital supply per capita with weights proportionate to the base period incomes going to labor and property, respectively. If we may equate productivity with earnings, we obtain a combined index of resources which has a particular meaning. It tells us how net national product per capita would have grown had the productivity of resources remained constant at base period levels while only the supplies of resources per head increased. Such an index, based on the twenties, rises only some 14 per cent between the seventies and the last decade. To account for the quadrupling of net national product per capita, the productivity of a representative unit of all resources must have increased some 250 per cent. This seems to imply that almost the entire increase in net product per capita is associated with the rise in productivity. This result may arise in some part from our choice of a base period. We chose a fairly recent base period, 1919-28, close to the valuation base of the national product estimates, 1929. Since the relative importance of service and property incomes remains fairly stable over the entire period (cf. Kuznets, "Long-Term Changes," pages 135137), and since capital increased far more rapidly than labor, the price of a unit of capital service must have fallen over time compared with that of a unit of labor. The choice of a fairly recent year as a base for our relatives in effect means weighting each unit of capital by a relatively low price.

Experiment, however, indicates that choice of base is of minor importance for the question at hand. If we shift the base of the index of resources to 1869-78, the increase of total input between 1869-78 and 1944-53 becomes 44 per cent. If we compare this with the rise of net national product per capita in 1929 prices, the indicated rise in productivity is still much greater, 175 per cent. This calculation, however, overstates the importance of the shift in base. If we shift the base for our resource index to $1869-78$, we should also value national product in the prices of that decade. This would, in all likelihood, make the trend of national product steeper and so indicate a greater increase in productivity than the 175 per cent mentioned above. (See Kuznets, "Long-Term Changes," pages 44-47.)

3. This result is surprising in the lopsided importance which it appears to give to productivity increase, and it should be, in a sense, sobering, if not discouraging, to students of economic growth. Since we know little about the causes of productivity increase, the indicated importance of this element may be taken to be some sort of measure of our ignorance about the causes of economic growth in the United States and some sort of indication of where we need to concentrate our attention. Since it will do little good to provide a catalogue of the possible causes of the rise in efficiency, I shall merely add two notes which have to 
do with a proper understanding of calculations which resolve the growth of output into the growth of resources and productivity, respectively. They will, I hope, also take some of the edge off my conclusion and serve to put the importance of factor input in somewhat better perspective.

First, although input of resources per capita has not increased much, this does not mean that the increase of resources has not contributed significantly to the rise in output per head. Total input of labor and capital has increased a great deal. Population more than tripled. The nearly constant number of man-hours per capita, therefore, meant a tripling of total man-hours. The tripling of capital per head meant a more than ninefold increase in total capital. The quadrupling of net national product per capita meant a twelvefold rise of total national product. But "the division of labor is limited by the extent of the market." If there is anything to the notion that when raw materials are plentiful resources and output will be connected according to a law of increasing returns to scale, then the great expansion of total resources must have contributed substantially to the increase in productivity.

Second, our calculations of resource inputs are based on usual definitions of labor supply and capital. These conventional methods of measuring resource inputs are faulty and, in the case of this country during the last seventy-five years, probably understate the increase in factor input. We therefore tend to overstate the rise in productivity.

On the side of labor, it is clear that the reduction in the importance of teenagers and old men in the labor force has concentrated employment in the age groups whose output per man is relatively high. It also seems likely that with the urbanization and commercialization of work there has been an increase in the intensity of labor. These changes may perhaps be offset by the augmented importance of women in the labor force. It seems possible, however, that a properly weighted index of man-hour input would have increased significantly over the period even if we leave out of account such matters as improvements in skill and managerial capacity which reflect training and other capital investment. (Cf. Kuznets, "Long-Term Changes," page 77.)

On the side of capital, there is a chronic underestimate of investment and accumulated stock because, for purposes of measurement, we identify capital formation with the net increase of land, structures, durable equipment, commodity stocks, and foreign claims. But underlying this conventional definition of investment is a more fundamental concept which is broader; namely, any use of resources which helps increase our output in future periods. And if we attempt to broaden the operational definition, then a number of additional categories of 
expenditures would have to be included, principally those for health, education and training, ${ }^{5}$ and research. These are fairly obvious because one is conscious both of an income motivation and an income effect. But there are other classes of expenditures where motives are mixed or disguised but which have at least the incidental effect of increasing productivity; namely, expenditures for food, clothing, and some recreation. The fact is that, in a thoroughly commercialized economy, disposing of a large surplus above its requirements for minimum consumption, very few expenditures are wholly without the aim and effect of increasing income. If this is so, effective capital formation, broadly conceived, must be sought in certain types of consumption and governmental expenditures as well as in conventional net investment.

The point of these two comments is simply that the relation between the contributions of resource expansion and of productivity growth is more complicated than our conventional measures can reveal. Two morals may be drawn. First, the long-term expansion of the labor supply must be restudied so as to provide a measure of the value of its changing composition as well as its changing size. And the expansion of the capital stock must be restudied to take account of a broader conception of accumulated resources. It may well be that we shall find it inconvenient to merge these additional categories of accumulation with conventional capital. But whatever our terminology, we have to pay close attention to all the ways our society uses its resources to increase its future product.

When all due allowance for the concealed increase in resource expansion has been made, however, there will remain a huge area to be explained as an increase in productivity. Our capital stock of knowledge concerning the organization and technique of production has grown at a phenomenal pace. A portion of this increase-presumably an increasing proportion-is due to an investment of resources in research, education, and the like. This part we may possibly be able to attribute accurately to the input of these resources insofar as we learn to trace the connection between such investment in knowledge and its marginal social contribution, as distinct from those small parts of its value which can be privately appropriated. Beyond this, however, lies the gradual growth of applied knowledge which is, no doubt, the result of human activity, but not of that kind of activity involving costly choice which we think of as economic input. To identify the causes which explain not only the rate at which our opportunities to raise efficiency increase but also the pace at which we take advantage of those opportunities

\footnotetext{
'A properly constructed index of labor input which gave due weight to the higher productivity of more highly educated or trained workers and to differences in vigor would be an alternative way to try to take these inputs into account.
} 
will, no doubt, remain the central problem in both the history and theory of our economic growth. The chief excuse for attempts to separate the measurable contributions of resources from those of productivity is to pose this problem as clearly as possible.

\section{The Trend of the Rate of Growth}

From these measures of the net expansion of output and resources since the Civil War, I turn next to the often asked question: has our rate of growth been slowing up. The retardation of growth in Great Britain and in other leading industrial countries and our own experience in the thirties have made the possibility of retardation a source of widespread anxiety.

Unfortunately, the information now available does not permit us to make a secure answer. The sources of error and bias in national product estimates-already noticed in connection with the measures of expansion-apply with aggravated force when we try to compare rates of growth at different times. We can often guess the direction in which national product estimates are biased, but in most cases we do not now know whether a particular bias affected the figures more strongly in one decade than another. It is clear, for example, that our inability to take consistent account of household production makes the rate of growth of national product too high during a period in which household production was giving way to commercial production. It is probable also that the rate of transfer from home to business changed over time. But did the transfer proceed more rapidly in the last quarter of the nineteenth century than in the second quarter of the twentieth, and by how much? This is the question relevant to changes in the rate of growth. We cannot answer it with any confidence. It is certain, therefore, that any statements about a long tendency in the rate of growth of national product must be treated with the greatest reserve unless the drift is so large and so persistent that no likely combination of biases and errors could account for it. In my judgment, the drift of the figures is not so clear. It is, nevertheless, worth while to review them, partly to check the bases for much current interpretation and speculation and partly because it is interesting to try to allocate the apparent changes in output growth to inputs and productivity.

Taking the figures as they stand, they give some indication of a slowing down in the rate of growth over the course of the eighty-odd years since 1870 . To see this, one has to take account not only of the ordinary business cycles, which generally run their course well within a decade, but also of the longer fluctuations which appear in the rate of growth of output. I shall have something more to say about these fluctuations in the next section. A smoothing of the data to eliminate 
both types of fluctuations suggests that total net product rose more rapidly during the last quarter of the nineteenth century than it did during the second quarter of the twentieth century. The apparent decline in the rate of growth of product per capita is less pronounced. ${ }^{6}$ (See chart.)

Whatever the showing of the figures, however, it is not at all clear that they are accurate enough for the purpose or, if accurate, that they represent the work of persistent forces in the economy. The very high rate of growth in the last quarter of the nineteenth century reflects an exceptionally high rate of increase during the late seventies and early eighties. If we neglect this apparently remarkable decade and take into account the possibilities of error and bias, the rates of growth afford no significant indication of retardation until we reach the depression of the thirties. ${ }^{7}$ The early figures of rapid growth are the last secure portions of the estimates. If valid, they may reflect a temporary surge of output. $^{8}$

On the other hand, the low rate of growth in the second quarter of the present century is entirely a reflection of the Great Depression. The rates of expansion since 1934 are as high as in any earlier period other than the (possibly exceptional) period in the late seventies and early eighties. They would look still higher on the basis of the Commerce figures than they do on the basis of the Kuznets estimates.

Whether there has been a significant degree of persistent retardation in the growth of national product per capita would, therefore, seem to turn on the answers to two questions presently unanswerable. Do the various biases and weaknesses in the estimates make for an appearance

\footnotetext{
- Kuznets' original estimates of net national product, which appear in the form of decade averages of annual data for overlapping decades, may be taken to eliminate most of the effects of ordinary business cycles. The same may be said of the rates of change between the overlapping decade averages (essentially rates of change per quinquennium). If we then take five-item moving averages of these rates of change (end items weighted one-half), we average experience for a twenty-year period, which is probably long enough to eliminate most of the effects of the longer fluctuations in the rates of growth. Both the quinquennial rates of change and the moving averages are shown in the chart.

"Compare Arthur F. Burns's conclusions for the period 1870-1930 based upon his study of physical output indexes. While he is highly skeptical about any conclusion which might be reached on the basis of the data available to him, he ventured to write: "... if there has been any decline in the rate of growth in the total physical production of this country, its extent has probably been slight, and it is even mildly probable that the rate of growth may have increased somewhat." (Cf. Production Trends in the U.S. Since 1870, page 279.) Since the retardation in the growth of the physical volume of production was almost certainly less than that in population, Burns felt it was still less probable that the growth of per capita output had been drifting downward.

B There is, indeed, some evidence that rates of growth were lower in the immediately preceding decades. After a discussion of W. I. King's older estimates for the period 1850-80, Professor Kuznets comments : "... the only safe comparison one can draw is that per capita real income did show some increase from 1850 to 1880 , perhaps as much as 50 per cent or more, perhaps as little as 20 per cent or less." This contrasts with Professor Kuznets' own estimate that per capita real income rose some 50 per cent in the single decade interval 1869-78 to 1879-88. Cf. Kuznets, "Long-Term Changes," p. 240.
} 


\section{CHART I}

Trends in Growth Rates, 1869-1953

- - Per cent change between overlapping decades *

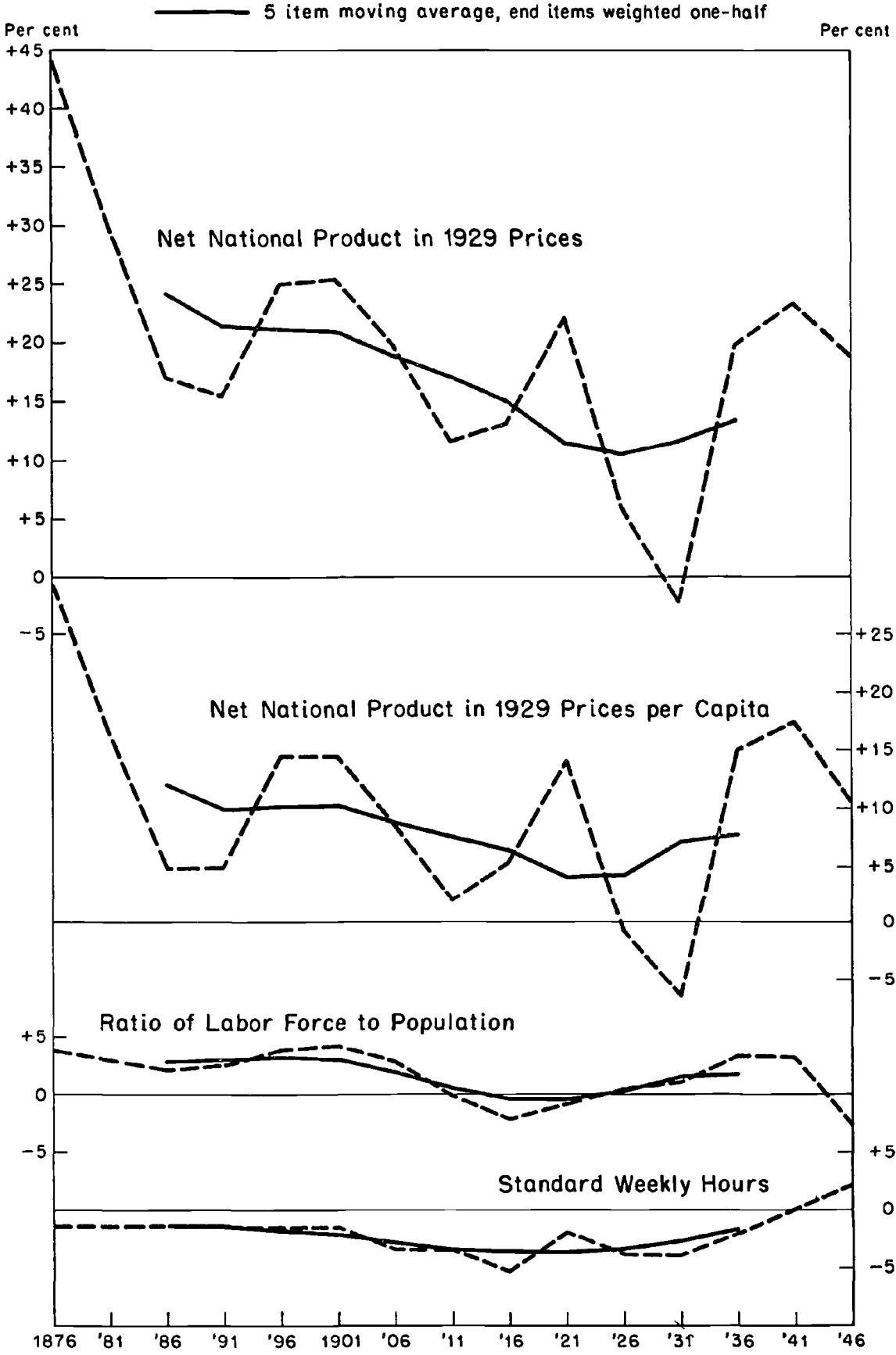

* Values are percentage rates of change since preceding overlapping decade. plotted at decade centers.

Sources: See notes to Table 1. 


\section{CHART II}

Trends in Growth Rates, 1869-1953

- - Per cent change between overlapping decades *

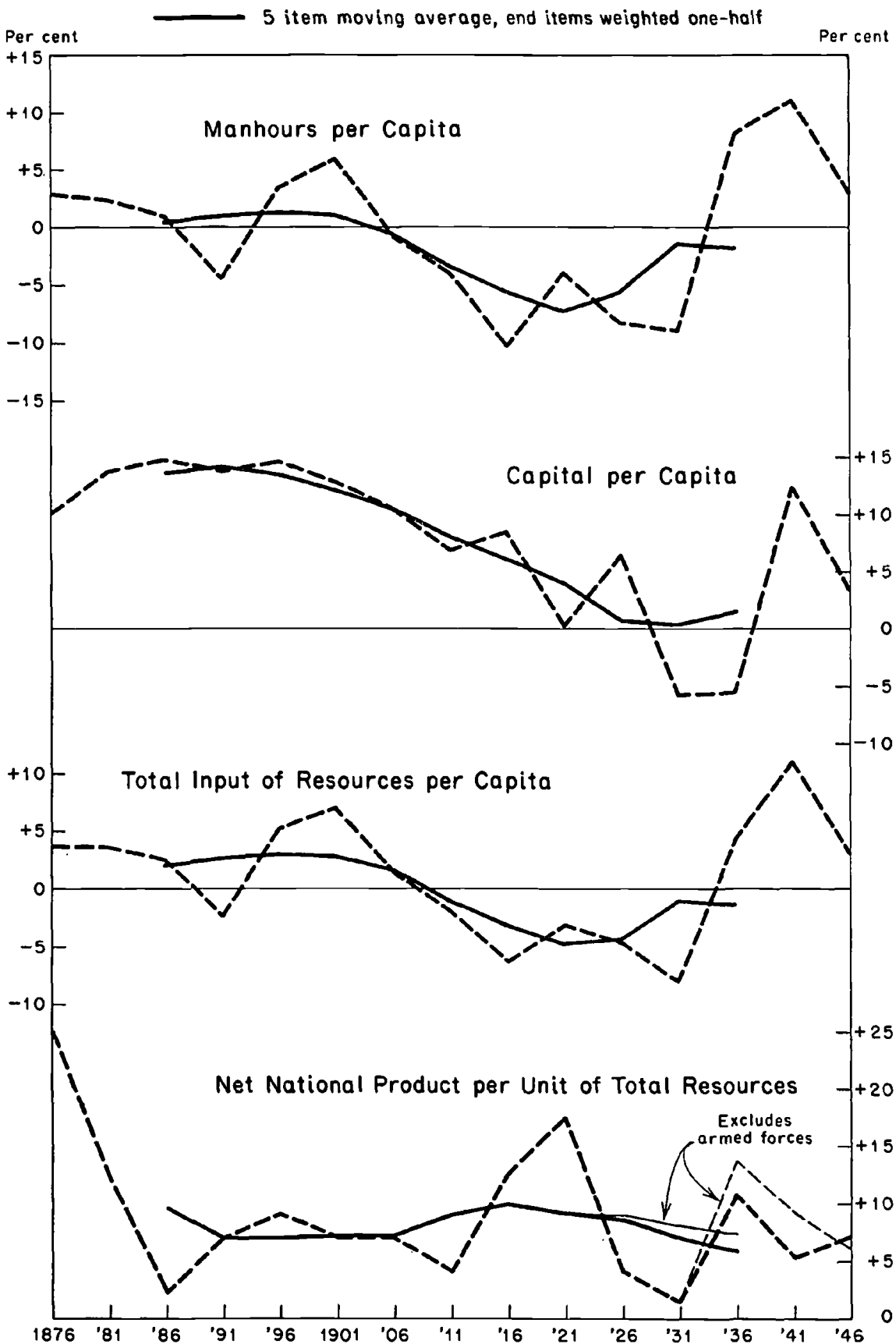

* Values are percentage rates of change since preceding overlapping decade, plotted at decade centers.

Sources: See notes to Table 1. 
of acceleration or retardation? Did the surge of the early years and the deep depression of the latter years represent fortuitous or persistent forces?

Whatever the answers to these important questions of history, it is possible to reach some conclusion with regard to the sources of the apparent retardation. Whatever tendency there may have been for growth of net product per capita to decline is traceable very largely, if not entirely, to a decline in the rate of growth of resources used per head of the population. Until the last two decades, which were years of accelerated growth both of input and output per capita, all the elements of resource input had grown less rapidly or declined more rapidly in later decades than in earlier. The ratio of labor force to population, which increased fairly steadily from 1870 until around 1910, thereafter fell, or grew very little, until the decade of the forties. With the exception of these recent years, hours of work fell at a more rapid rate during the 1900's than during the late 1800's. As a result, man-hours per head rose at a declining rate until the turn of the century and then fell at an increasing pace until the mid-thirties. One may add that the diversion of labor force to military purposes increased over time. So the decline in the rate of growth of civilian man-hours per head was even more pronounced than in that of total man-hours. In the thirties, of course, great unemployment was an aggravating element. The growth of capital per head, as conventionally measured, slowed down drastically. It rose at a constantly slower rate until the end of the twenties, and then declined during the depression. In spite of rapid growth during the last fifteen years, capital per head in the late forties was only a little more plentiful than in the twenties. Until relatively recent years, therefore, every major element of resources made for retardation in the growth of net product per capita. The combined index of resources per capita rose at a declining rate until the early 1900's and then fell at an increasing rate until the middle thirties.

It was these changes in the growth of resources per head which account for most, if not all, the retardation in the growth of net product per capita recorded in the estimates. Productivity per man-hour, on the other hand, has been rising at a fairly constant rate since the eighties, and this trend has dominated the movement of the productivity of all resources. The productivity of capital, taken alone, seemed to be falling until about World War I. It has been rising since, a fact which has helped to maintain the rate of rise in the productivity of all resources. The essential constancy in the rate of rise of productivity is perhaps the most significant single fact which emerges from a review of our economic record since the Civil War. ${ }^{9}$ Whether this reflects an es-

"It is a "fact" heavily qualified by all the errors and biases in the national product 
sentially unweakened capacity to increase the efficiency of our resources in the future is perhaps the most significant single question which requires an answer.

\section{Fluctuations in the Rate of Growth}

The trend of the rate of increase of national product, whether constant or slowly declining, is a generalization concerning our growth which abstracts from its fluctuations and pretends to describe only its persistent or underlying movement. But, of course, the growth of output in reality is anything but steady. It rarely runs in the same direction for many months and almost never for even two months at the same rate.

We have learned to think of these alterations of the rate of growth as in part accidental and in part systematic. Aside from seasonal fluctuations, the systematic movement principally identified in the past has been the short-term business cycle either in its minor or major variant. If, however, to reveal the secular trend in output we calculate moving averages for periods long enough to eliminate business cycles (nineyear moving averages, for example), the resulting curve of output for the period since 1870 still reveals striking fluctuations-not in the level of output but in its rate of growth. The curve mounts relatively steeply for a time and then exhibits retardation in a pattern which has repeated itself roughly every twenty years. The same observations

figures and in the estimates of labor input and capital. Moreover, it measures both labor input and capital in a fashion which neglects some increase in labor inputi due to change in the age composition of the labor force and probably in the intensity of work. It also neglects the fact that a substantial volume of resources has been devoted to the improvement of intangible capital: technology, labor skills, health, and organization. The rate of accumulation of such intangible capital may be increasing. It is a "fact" which is somewhat bolstered by the showing of other over-all measures of productivity. These measures, to which I refer below, are not based on data which are wholly independent of those on which I rely, but they involve some degree of independence and they are each calculated on a somewhat different plan: (1) John W. Kendrick's estimate of "national output per unit of unit of labor and capital combined," 1899-1953, shows no retardation in growth. Its rate of growth since 1919 is somewhat greater than it was in the two earlier decades. (National Bureau of Economic Research, 35th Annual Report, May, 1955, page 45.) (2) The Twentieth Century Fund estimate of "real private national income per private manhour," 1850-1952, has a trend which suggests a mild degree of acceleration. (Dewhurst and Associates, op. cit., pp. 39-42.) (3) Jacob Schmookler's estimate of gross national product per combined unit of labor and capital, 1869-1938, shows no tendency to retardation in growth after the first decade. (Op. cit., Table 9.) (4) Harold Barger's estimates of productivity per man-hour in commodity production (agriculture, mining, and manufacturing) and distribution, 1869-1949, show either a steady rate of growth or else acceleration, whether taken individually or in combination. Since Barger's estimates are based on indexes of the physical volume of production in the four industrial branches, his figures are more nearly independent of our own than are the other alternatives. Barger's figures take no account of productivity in the service industries other than distribution. It is possible that a productivity index for the remainder of the service trades, if one could be devised, would change the picture. ( $D$ istribution's Place in the American Economy since 1869, National Bureau of Economic Research, 1955, pp. 37-41.) 
may be made if one calculates rates of increase in decade averages of output for overlapping decades (see chart). (Cf. Kuznets, "Long-Term Changes," pages 48-57.) The possibility, therefore, arises that there is a significant cycle in the secular trend of output-meaning by this, movements which persist over a period longer than a business cyclewith an approximate duration of twenty years. ${ }^{10}$

In relatively recent times, the hypothesis of a twenty-year growth cycle starts with Kuznets' early work on secular trends in which he suggested the existence of fluctuations of this duration in the rate of growth of production of many individual commodities, in the rate of rise of many prices, and in several other types of time series. (Secular Trends in Production and Prices, Houghton Mifflin, 1930, Chapter IV.) The hypothesis was then taken up by Arthur F. Burns in his Production Trends in the United States Since 1870 (National Bureau of Economic Research, 1934, Chapter V), in which he showed not only that twenty-year growth cycles were characteristic of the output of many commodities but also that the cycle was general in the sense that the growth cycles of different commodities tended to concur in time and that they also appeared in indexes of aggregate industrial production. Burns also found his secular swings in nonagricultural prices, in shares traded, in business failures, and in patents issued. Finally Kuznets in later work has shown that the same swings appear in his long-term estimates of gross and net national product ("Long-Term Changes," pages 48-57), in labor productivity, in population and immigration (with a lag), and in residential construction (with a longer lag). ${ }^{11}$ Unpublished work by Kuznets and Dorothy S. Thomas carries the subject further, particularly as regards population change, internal migration, construction, and certain financial series. Still others suggest the presence of a similar cycle in foreign countries. ${ }^{12}$ Both

\footnotetext{
${ }^{10}$ Although my discussion is restricted to the twenty-year cycle, I do not mean to suggest that the secular trend of output may not be subject to other significant types of fluctuations. If it is, however, their period is too long to be distinguished clearly from the underlying trend in a review covering some seventy to eighty years.

${ }^{11}$ Simon Kuznets and Ernest Rubin, Immigration and the Foreign Born (National Bureau of Economic Research, "Occasional Paper 46," 1954), pp. 30-34. The findings of this paper are, to some extent, similar to those of Brinley Thomas.

${ }^{12}$ See Walter Hoffman, British Industry, 1700-1950 (Oxford: Blackwell, 1955; a translation of the German original published 1940), Part C. Brinley Thomas (Migration and Economic Growth, Cambridge, 1954, especially Chaps. VII and VIII) argues that there were twenty-year cycles in the United States (and, to some extent, Canada and Australia) connected by immigration and capital movements to inverted cycles in Great Britain, Sweden, and perhaps Germany. B. Weber and S. J. Handfield-Jones ("Variations in the Rate of Economic Growth in the U.S.A., 1869-1938," Oxford Economic Papers, June, 1954, pp. 101-131) attempt to connect the long waves in Kuznets' figures for national product with successive waves of innovation in the application of steam power to industry and transport (1870-82), in the further extension of steam and steel and in the development of new resources (1894-1907), and in electricity, industrial chemicals, and the internal combustion engine (1919-29).
} 
Kuznets and Burns considered their work only exploratory and neither was persuaded that the evidence so far accumulated established the existence of significant recurrence of movement; that is, of true cycles.

Kuznets finds three complete swings in the rate of growth in the period since 1870 and one incomplete swing - a rise beginning 1932 and (tentatively) reaching its peak in $1945 .{ }^{13}$ The variation in the rate of growth between the expansion and contraction phases of the growth cycles is large compared with the average rate of growth itself. For example, in the period 1873-1926, that is, before the huge fluctuations associated with the Great Depression and World War II, the over-all average rate of rise of GNP per worker was about 20 per cent per decade. But the average rate of growth in upswing periods was about five times as rapid as in the downswing periods. The average difference between the rate of growth in the upswing periods and that in the downswing periods was as large as the average rate of growth itself..$^{14}$ If we add the last long swing, which covers the Great Depression and the upswing of the forties, the size of the average fluctuation becomes very much greater than the average rate of growth.

The significance of these long swings is not yet established. At least two possibilities are present which would rob the observed fluctuations of most of their meaning. It may be that what we observe are only accidental variations in the severity or duration of ordinary business cycles, which assume the appearance of long swings when their effects are stretched out and smoothed by moving averages or some similar device. And even if it is true that the swings reflect forces which operate over periods longer than business cycles, it may still be true that these forces are predominantly irregular and haphazard.

12 The suggested chronology runs as follows:

$\begin{array}{cc}\text { Trough } & \text { Peak } \\ 1873 & 1884 \\ 1892 & 1903 \\ 1912 & 1926 \\ 1932 & 1945\end{array}$

The dates were determined by observing a graph of a nine-year moving average of GNP per worker in 1929 prices and locating the points at which the slope became significantly steeper and flatter. The first and last dates are set only tentatively until the data can be extended far enough backwards and forwards to confirm the position of the inflection point. This chronology was presented in an unpublished memorandum, "Swings in the Rate of Secular Growth," prepared for the Capital Requirements Study of the National Bureau (March, 1952). A similar chronology based on the movement of rates of change of net national product in 1929 prices between overlapping decades appears in "Long-Term Changes," p. 55. An earlier chronology, based on the consensus of many commodity production series, but containing an extra cycle in the decade 1910-20, was presented by A. F. Burns, op. cit., p. 196. Since but few examples have as yet been traced in the American data, neither the average duration of the alleged cycle nor its variability can be considered established.

${ }_{14}$ These are geometric means weighted by the duration of phases. The data are from Kuznets' memorandum, "Swings in the Rate of Secular Growth." 
These negative possibilities cannot now be dismissed. Indeed the influence upon the swings so far experienced in this country of substantial irregular forces was patent and undeniable. Thus it seems reasonable to attribute some significant responsibility for the swing beginning around 1873 to the recovery from the Civil War, for the swing beginning around 1912 and continuing through the twenties to World War I, and for the swing beginning in 1932 and continuing into the forties to World War II. It would be impossible to try to review the considerable body of relevant evidence in the short space available to me. For purposes of this discussion, I can simply record my conviction that there is sufficient evidence to make the long-swing hypothesis worthy of closer investigation. ${ }^{15}$

If supported by further study, the long-swing hypothesis promises to make a serious contribution to our understanding of economic change. I shall cite three reasons:

First, if it be true that the long swings reflect, in significant degree, the operation of systematic responses to either regular or irregular stimuli, then study of our past growth will best be organized in periods corresponding to the long swings. And a proper understanding of these waves of growth will presuppose an ability to separate the unique from the recurrent forces at work in each period.

${ }^{25}$ Merely to indicate that this position has some tangible basis, one may cite the following:

A. In support of the proposition that the long swings are more than merely an illusory reflection of business cycles: (1) The persistence of long swings in figures arranged to show average levels in identified business cycles (Kuznets, "Swings in the Rate of Secular Growth"). (2) The persistence of long swings in figures for business cycle peaks alone, which thus partially eliminate the effects of long and deep depressions (ibid.).

(3) The existence of long swings in British data which, at least for 1870-1914, appear to fluctuate inversely to the swings in this country, whereas the normal business cycle relation is positive (B. Thomas, op. cit., Chap. VII). (4) The fact that the period required for the exploitation of major innovations or new territory is certainly longer than the five or six years associated with even major business expansions. This does not account for the twelve or thirteen year long-swing expansions or for twenty-year cycles, but it argues for the presence of unsteady expansive stimuli which carry over from one business cycle to another.

B. In support of the view that the long swings exhibit at least some regular features, in addition to the impact of many irregular circumstances, confident assertion is prevented by lack of study and by the fact that U.S. production data in fair quantity now reach back only to 1860 and, therefore, reveal only three and one-half long swings. Subject to these limitations, there are clear hints of regularities which suggest the presence of an internal structure with some stability. I refer only to certain prominent observations in published sources: (1) Burns's finding that during periods of long-swing expansion, the rates of growth of production of different commodities become increasingly different and that this dispersion of the rates of growth declines in long-swing contractions (Production Trends, pp. 242-247). (2) Burns's finding that each period of long-swing expansion is followed by a business cycle depression of great severity, a finding which he tentatively connects with the increasing dispersion in the rate of expansion of individual industries during the upswing (ibid., pp. 247-253). (3) Kuznets' and Rubin's finding ("Immigration and the Foreign Born") confirming B. Thomas' finding (op. cit., Chaps. VII and VIII) concerning the lagged response of immigration to the rate of growth of output, and Kuznets' finding that the rate of increase of population showed a lagged response to economic growth ("Long-Term Changes," p. 55). (4) The common finding (cf. Kuznets and Rubin, op. cit.) that there is a lagged response of construction to population growth. 
Second, the long swings appear to represent fluctuations in productivity growth and in the increase of manpower and capital to a greater degree than business cycles whose most prominent characteristic is that they are fluctuations in the intensity with which resources are employed. (Before the Great Depression, quinquennial changes in the level of employment were not well correlated with the long swings in the rate of growth of output, nor were the magnitude of the changes in employment percentages comparable in size with those in output. Cf. Kuznets, "Long-Term Changes," Tables 3 and 10. These facts also bear on the question of the independence of the longer swings from business cycles. It is not yet clear, however, that the unemployment figures are sufficiently accurate for the purpose, and the conclusion needs to be checked by further study.) Unless it turns out that fluctuations in the growth of productivity or of resource supply are themselves chiefly governed by business cycle movements, we must anticipate fluctuations in the rate of growth of output even if we succeed in maintaining employment at high levels. Since past fluctuations in the rate of growth were wide relative to its long-term average, projections of output looking forward a decade or two-such as are often madewould need to take into account the current phase of the long swing. This presupposes a capacity to define the recurrent features of long swings-something we cannot do today.

Finally, our past experience with long swings shows that every upswing in the rate of growth has terminated in a depression of great severity. This may, as Burns tentatively suggested (see footnote 10 above), be connected with a tendency for growth to become increasingly unbalanced as the upswing proceeds, presumably leading to a decline of investment in the overexpanded industries. Or a mere slowing down of the rate of growth of output for any reason may lead to a reduction of investment, as one variant of the Harrod-Domar theory suggests. In either case, there is reason to expect that whenever our rate of progress begins to slow down markedly, forces will also be present making for serious depression. Such depressions will not necessarily be experienced in view of the role government may play in counteracting them. But certainly the wisdom and energy of the government will be put to a severe test. The experience with long swings suggests that our liability to severe depression may be a normal part of a swing in the rate of growth, which may itself be due, in part, to recurrent causes. If these could be identified and better understood, our ability to prepare for, and to meet, the emergency of depression would undoubtedly be enhanced. 